\title{
A Qualitative Study Exploring Barriers, Facilitators and Solutions to Equitable Coverage of Preventive Chemotherapy Towards the Control and Elimination of Neglected Tropical Diseases in South Omo Zone, Nomadic Setting of Southern Ethiopia: Stakeholders' Perspectives and Experiences
}

Mekuria Asnakew Asfaw ( $D$ maksambaramr23@gmail.com )

Arba Minch University https://orcid.org/0000-0002-5718-0001

Chernet Hailu

Jimma University

Tariku J. Beyene

The Ohio State University

Research Article

Keywords: Barriers, Facilitators, Solutions, Preventive chemotherapy, Neglected Tropical Diseases, Elimination, Nomadic and remote settings, Equity, PC-NTDs

Posted Date: January 25th, 2021

DOI: https://doi.org/10.21203/rs.3.rs-152413/v1

License: (c) (i) This work is licensed under a Creative Commons Attribution 4.0 International License. Read Full License 


\section{Abstract}

\section{Background}

Despite substantial progress made towards the control and elimination neglected tropical diseases (NTDs) in Ethiopia using preventive chemotherapy (PC) for lymphatic filariasis, onchocerciasis, schistosomiasis, trachoma, and soil-transmitted helminths, its implementation is facing challenges to achieve equitable coverage especially under mobile populations. This study, therefore, aimed at exploring multiple stakeholders' perspectives and experiences on barriers, facilitators, and potential solutions to equitable coverage of PC in a mobile nomadic setting of Southern Ethiopia.

\section{Methods}

This study was conducted in the South Omo zone in August 2019. Qualitative data collection methods involving key informant interviews (KIIs) and focus group discussions (FGDs) were used to collect data from a total of 27 KIls and 16 FGDs in a nomadic community of Southern Ethiopia using a semistructured tool. Data were analyzed using a thematic approach, supported by NVivo 11 software.

Results

This study revealed multiple barriers affecting equitable access and use of PC, and its facilitators and possible solutions were revealed by taking four dimensions (availability, accessibility, acceptability, and effective coverage) into consideration. The emerged barriers were lack of resource and infrastructure; inadequate information, mobilization and community engagement, lack of awareness, inappropriate scheduling of MDA, distribution of drugs at central point, mobile nature of nomadic communities, security challenges, low school attendance, misconception, misbelief, distrust of government, rumor and drugs' side-effects, lack of community drug distributors' (CDDs') motivation, weak leadership and supportive system. On the other hand, the emerged facilitators were the provision of drugs at no-cost, partners' support, the presence of the religious and cultural organization, and decentralization of services. The possible suggested solutions were increasing partnership, improve supervision, engaging parents in mass drug administration (MDA), arrange a visiting schedule out of working hours, involve the village chief in training, intensify awareness creation, home-to-home visit, and plan mop-up activities.

\section{Conclusions}

There is a need of addressing barriers that affect efforts in equitable implementation of MDA to ensure no one is left behind from PC in nomadic settings of Southern Ethiopia. Most importantly, information, mobilization and community engagement, mobile nature of the nomadic community, and high level of low school attendance should take special consideration when MDA is planned in these settings.

\section{Introduction}


Neglected Tropical Diseases (NTDs) are a group of communicable diseases, disproportionately affect 1.5 billion people globally in 149 countries and territories $[1,2,3]$. About $90 \%$ of the total NTDs burden is contributed by five diseases - lymphatic filariasis, onchocerciasis, schistosomiasis, soil-transmitted helminthiases, and blinding trachoma[4]. These diseases impose substantial health and socio-economic burdens including physical and intellectual impairments, school non-attendance among children, and reducing economic productivity $[4,5]$. The African continent bears $39 \%$ of the total global burden of NTDs [3], and Ethiopia has a high burden of NTDs in sub-Saharan Africa (SSA) [6].

The World Health Organization (WHO) recommends periodic, inexpensive, and safe preventive chemotherapy (PC) as the main public health intervention for the control and elimination of NTDs [7]. Out of the 1.5 billion populations affected by NTDs, $90 \%$ is accounted for by PC-NTDs. And up to 44 countries in the African region are endemic for at least 1 PC-NTD, 42 for at least 2 PC-NTDs, and 17 for all the 5 PCNTDs [3]. An estimated 5.9 million years of healthy life were lost in SSA due to schistosomiasis (SCH), onchocerciasis (OV), lymphatic filariasis (LF), and soil-transmitted helminthiasis (STH) in 2013 [5]. Epidemiological studies revealed wide geographic overlap among these diseases, particularly in disadvantaged populations with limited access to health services and sanitation [8].

Ensuring equity in the prevention of NTDs is crucial to reach NTDs elimination goals, which is greatly linked with sustainable development goals to ensure equity of health service access in Goal 3 (target 3.3) as well as to inform universal health coverage $(\mathrm{UHC})[9,10]$. It is often expected that NTD interventions are equitable and meet the needs of all groups in the population because efforts are already targeted at populations that are largely poor and rural. However, segments of the population remain not reached and there are areas of persistent disease transmission because of inequity of PC coverage [11-13]. While focusing on PC, global NTD initiatives have largely ignored other manifestations of neglect, such as equity and social determinants of health [6]. PC coverage could be affected by a range of individual, household, social, cultural, economic, and health system factors that could challenge the implementation of PC programs [4].

Ethiopia has been implementing PC as the main strategy to tackle PC-NTDs, and recent reports of drug treatment coverage showed remarkable progress - reaching a significant proportion of people in need $[13,14]$. However, routine therapeutic coverage reports of MDA showed low coverage of PC at South Omo district, a nomadic setting of the South Omo, as reported by the Ethiopian Federal Ministry of Health (FMoH) in 2018 [15]. This low coverage could be attributed to various challenges invisible to implementers. However, little evidence exist on these potential barriers to equitable access and use of PC at South Omo in Ethiopia particularly in nomadic and hard-to-reach areas. This study, therefore, aimed to explore stakeholders' perspectives and experiences on these gaps and participatory proposals on facilitators and solutions suggested by these stakeholders. We hypothesize that communities affected by PC-NTDs in the South Omo zone have inequitable access and use of PC services due to barriers - at individual, community, household, and health system levels.

\section{Methods}




\section{Study design and period}

A qualitative study was conducted August 2019 that involved both KIls and FGDs to gain an in-depth understanding of stakeholders' perspectives and experiences on barriers, facilitators, and solutions to equitable access and use of PC. KIIs and FGD sessions are reported according to the consolidated criteria for reporting qualitative research framework [16].

\section{Study setting}

The study was done in the South Omo zone, Southern Ethiopia. The population in the zone is estimated to be 577,673 (288, 638 males and 289,035 females), according to the central statistical authority (CSA) in 2007 [17]. The zone has nine districts (which consists of both agrarian and nomadic communities). All PC-NTDs are known to be endemic in the zone and preventive chemotherapy has been put in place in the health system to tackle PC-NTDs [13]. The town, Jinka, is located at $770 \mathrm{~km}$ to the southwest of Addis Ababa or $540 \mathrm{~km}$ from Hawassa, the capital of Southern Nations, Nationalities and Peoples' Region [18].

\section{Study populations}

The study populations include community members who are involved in at least one round of MDA, community drug distributors (health extension workers and community members), and teachers in focus group discussions. On the other hand, all potential key informants from the community, health system, and other sectors were involved in the key informant interview. The selected key informants were NTDs focal points, NTDs program managers, health facility head, primary health care unit-in charge, the village chief, school director, and head of women and social affairs.

\section{Inclusion and exclusion criteria}

Community members who have received at least one round of MDA but preferably 2 treatment rounds of PC treatment and community drug distributors (teachers, health extension workers, and teachers) participated in the focus group discussion. Any individuals who were a potential source of information regarding MDA participated in the key informant interview. On the contrary, individuals with a serious illness during the survey were excluded.

\section{Sample size and sampling technique}

Participants were recruited from seven districts. First, lists of districts with low coverage of PC and or with a history of MDA interrupted in 2019 were identified from our earlier baseline study as well as from record data of the South Omo zone health department. Then, by taking information saturation and homogeneity and or heterogeneity and locations (urban/semi-urban/remoteness) into consideration, sampling was performed. A total of sixteen FGDs and twenty-seven Klls were conducted. Averaging at least 8 participants per session in FGD were involved. Due to differences in coverage of PC between males and females, gender norms were considered as criteria for the composition of groups. Moreover, the number of participants in FGDs and KIls was determined based on their relevance to the study.

\section{Study variables}


Variables included in this study were barriers, facilitators, solutions to equitable access and use to PC for PC-NTDs, and availability, accessibility, acceptability, and effective coverage were taken into consideration to collect data on equity of PC.

\section{Data collection}

Key informant interviews and focus group discussions were conducted using semi-structured interview guides. A team of experienced qualitative research experts with social and public health professionals collected the data. All materials used for the study were developed in the English language, and then translated into the local language and then back to English. The FGDs and KIls were conducted at places where convenient for discussion and interview after working hours. The FGDs were led by a moderator and a note-taker using an FGD guide and a voice recorder was conducted at offices or places where the suitable place for an interview. Also, an interview guide was used for Klls.

The FGDs were held after the completion of any key informant interviews; and consideration was given to keep homogeneity of participants. This is due to our assumption of certain issues arising during Klls that could lead to modification of the composition of the groups and types of issues to be addressed

\section{Data management and analysis}

All KIls and FGDs were audio-recorded, transcribed, and translated verbatim into English by the data collectors who had conducted the KIIs or FGD immediately after data collection. Thematic approach, a method for identifying themes in the transcripts were used for data analysis, using NVivo 11.0 software [19]. After an initial reading of the transcripts, all interviews were coded initially for emerging core descriptive content; these themes are discussed in greater detail in the results section.

\section{Operational definitions}

Equity in health indicates that ideally everyone should have a fair opportunity to attain their full health potential, and no one should be disadvantaged from attaining this potential [22]. Hence, in this study, equity is defined as anyone eligible for PC should not be left behind from accessing and use of PC.

Effective PC coverage is defined as people who need health services get them in a timely fashion at a level of quality necessary to obtain the desired effect [20].

\section{Data quality}

Data quality was kept throughout the research process through pre-testing and standardizing tools; training of data collectors and supervisors; and daily checking of consistency and accuracy of data were made by supevisors.

\section{Community engagement in the research process}

The research process involved community representatives during gaps identification and data collection. Health professionals and social workers from the community were involved in the data collection. 


\section{Results}

\section{Socio-demographic characteristics of participants}

A total of 155 participants (27 KIls and 16 FGDs) were involved from 7 districts, mainly from nomadic and remote settings. Of the 155 individuals, 128 participated in 16 FGD sessions, averaging at least 8 individuals per session. Participants in Klls were primary health care unit-in charge, district NTDs focal points, zonal and regional NTD program managers, health center heads, village chief, school directors, and women and child issues department heads (Table 1).

Table 1

Particpants in key informant interviews

\begin{tabular}{|ll|}
\hline Participants & Number of interviews \\
\hline Primary health care unit-in charge & 6 \\
\hline District NTDs focal point & 7 \\
\hline Health center head & 5 \\
\hline Women and child issues department head & 1 \\
\hline Village chief & 2 \\
\hline Total & 27 \\
\hline
\end{tabular}

FGDs participants were community members (anyone who received at least one round of MDA including religious leaders and school-aged children), while drug distributors (CDDs) were health extension workers, health development army, and teachers (Table 2).

Table 2

Particpants in focus group discussions

\begin{tabular}{|ll|}
\hline Participants & Number of FGDs \\
\hline Community members & 8 \\
\hline Community drug distributors & 7 \\
\hline Teachers & 1 \\
\hline Total & 16 \\
\hline
\end{tabular}

\section{Barriers, facilitators, and solutions to equitable access and use of PC}

Results are presented in three main categories (barriers, facilitators, and solutions) and themes with relevant verbatim quotes regarding equitable access and use of PC by taking four dimensions (availability, accessibility, acceptability, and effective coverage) into consideration. This study explored 
the perspectives and experiences of stakeholders who participated in the MDA process. In cases where views are specific to particular participants, these are noted within the manuscript.

The emerged barriers to equitable access and use of PC were lack of resources (financial, human, communication and vehicle), low community drug distributor's motivation; inadequate information, mobilization and community engagement, lack of awareness, inappropriate scheduling of MDA, mobile nature of nomadic communities, security challenge, low school attendance, drugs distribution at central point, scatter pattern of households, misconception, misbelief, distrust of government, lack of PC program ownership; rumor and drugs' side-effects; and weak planning, leadership, supportive system, and coordination (Table 3).

On the other hand, the emerged facilitators to equitable access and use of PC were the presence of community structure (health development army), provision of drugs free of charge, availability of community volunteers, the presence of community health workers, partners support to train drug distributor, the presence of the religious and cultural organization, and decentralization of government structure to smallest point (kebele) (Table 3) 
Table 3

Potential barriers, facilitators, and solutions to equitable access and use of PC, South Omo zone, 2019.

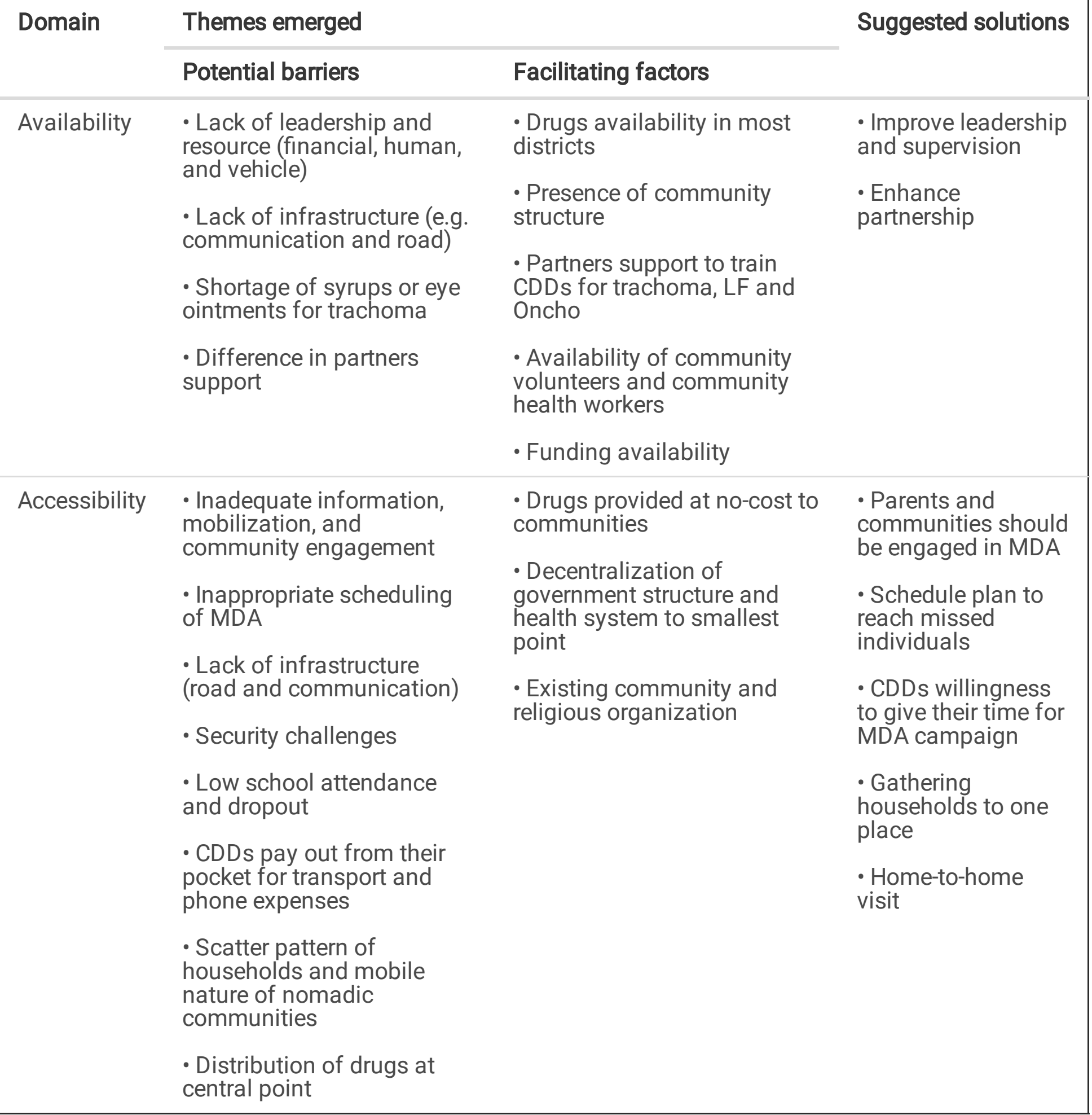


Table 3

(Continued)

\begin{tabular}{|c|c|c|c|}
\hline \multirow[t]{2}{*}{ Domain } & \multicolumn{2}{|l|}{ Themes emerged } & \multirow[t]{2}{*}{ Suggested solutions } \\
\hline & Potential barriers & Facilitating factors & \\
\hline Acceptability & $\begin{array}{l}\text { - Living in semi-urban } \\
\text { area } \\
\text { - Concern about side- } \\
\text { effects } \\
\text { - Refusal of treatment } \\
\text { - Misconception on PC } \\
\text { - Misbelief related to } \\
\text { drugs } \\
\text { - Lack of community } \\
\text { awareness on NTDs } \\
\text { and PC } \\
\text { - Lack of ownership of } \\
\text { PC program } \\
\text { - Lack of parents' } \\
\text { consent } \\
\text { - Unfavorable gender } \\
\text { and cultural norms } \\
\text { - Low attention given to } \\
\text { NTDs and PC } \\
\text { - Distrust of } \\
\text { government } \\
\text { - Unfavorable gender } \\
\text { and cultural related } \\
\text { norms }\end{array}$ & $\begin{array}{l}\text { - Selection of CDDs } \\
\text { from and by } \\
\text { community } \\
\text { - Community demand } \\
\text { for drugs } \\
\text { - Presence of } \\
\text { religious and cultural } \\
\text { organization } \\
\text { - Experience on drugs } \\
\text { - Awareness creation }\end{array}$ & $\begin{array}{l}\text { - Involvement of kebele leaders } \\
\text { in training } \\
\text { - Arrange scheduling visits to } \\
\text { reach people at their work place } \\
\text { - Creating national MDA day } \\
\text { - Sustained awareness creation } \\
\text { activity } \\
\text { - Promote benefits of drugs by } \\
\text { model individuals } \\
\text { - Deliver drugs early in the } \\
\text { morning } \\
\text { - Involve religious leaders } \\
\text { - Involve teachers in school } \\
\text { deworming }\end{array}$ \\
\hline
\end{tabular}




\begin{tabular}{|c|c|c|c|}
\hline \multirow[t]{2}{*}{ Domain } & \multicolumn{2}{|l|}{ Themes emerged } & \multirow[t]{2}{*}{ Suggested solutions } \\
\hline & Potential barriers & Facilitating factors & \\
\hline \multirow[t]{10}{*}{$\begin{array}{l}\text { Effective } \\
\text { coverage }\end{array}$} & $\begin{array}{l}\text { - Weak leadership, } \\
\text { planning, coordination } \\
\text { and supervision }\end{array}$ & $\begin{array}{l}\text { - CDDs directly } \\
\text { observe while people } \\
\text { wallowing drugs }\end{array}$ & $\begin{array}{l}\text { - Improving planning including } \\
\text { mop-up activities, coordination, } \\
\text { and supervision }\end{array}$ \\
\hline & $\begin{array}{l}\text { - Conducting MDA } \\
\text { during fasting time }\end{array}$ & & $\begin{array}{l}\text { - Intensive, supervision, } \\
\text { monitoring and regular follow-up }\end{array}$ \\
\hline & $\begin{array}{l}- \text { Lack of CDDs and } \\
\text { teachers motivation }\end{array}$ & & $\begin{array}{l}\text { - Integrate MDA in routine health } \\
\text { program }\end{array}$ \\
\hline & - Lack of support from & & - Improve per-diem for CDDs \\
\hline & 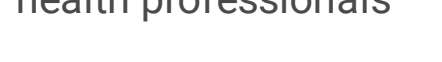 & & - Increase political commitment \\
\hline & $\begin{array}{l}\text { - Lack of resources to } \\
\text { cover costs for drug } \\
\text { distributors }\end{array}$ & & \\
\hline & $\begin{array}{l}\text { - Lack of mop-up } \\
\text { activities }\end{array}$ & & \\
\hline & $\begin{array}{l}\cdot \text { High turnover of } \\
\text { trained health } \\
\text { professionals }\end{array}$ & & \\
\hline & $\begin{array}{l}\text { - Low political } \\
\text { commitment }\end{array}$ & & \\
\hline & $\begin{array}{l}\text { - Lack of media } \\
\text { coverage }\end{array}$ & & \\
\hline
\end{tabular}

\section{Barriers to equitable access and use to PC}

Challenges related to the availability of drugs, such as lack of leadership, resources and infrastructures (financial, communication, roads, and vehicle) could affect access and use of PC in the communities affected by NTDs, as revealed with the following quotes.

"...Although drugs were provided for STH and SCH to Hamer district from supplier, it was not distributed to SAC due to lack of leadership. Besides, at districts where drugs were available, CDDs were unable to get around communities due to lack of resource and infrastructure..." [Key informant, NTDs focal point]

"...Even CDDs move on foot to reach their communities. Moreover, lack of vehicles affects to conduct supervision..." [Key informant, NTDs program manager]

Shortage of syrups or eye ointments for trachoma

"...Sometimes lack of convenient drugs formulation for children, for example, zithromax syrups and eye ointments for trachoma affect the uptake of drugs..." [Key informant, primary health care unit-in charge] 
"...Lack of CDDs and supporting professionals adversely affect the MDA process. For example, a single HEW visited our school to distribute drugs, and in some kebeles there are no HEWs..." [Key informant, school director]

“..High turnover of trained health professionals adversely affect the implementation of MDA...] [Key informant, NTD program manager]

Difference in partners support

“...Difference in partners support to train CDDs for different PC-NTDs affects the implementation of MDA through creating perception difference. For instance, partners for trachoma, oncho and LF paid much periderm compared to SCH-STH programs..." [Key informant, NTDs focal point]

Study participants stated that access to PC could affect the reach of PC in different ways, as illustrated below.

Inadequate information, mobilization, and community engagement

Most participants ( $\geq 75 \%$ ) repeatedly mentioned that lack of access to information, mobilization, and community engagement as the main barriers to the equitable access of PC. These barriers include a lack of sufficient and relevant information about PC drugs, their purpose, and possible side-effects.

“...Usually community people did not receive adequate information and not well communicated on purpose, benefits, and side-effects of drugs ahead of the MDA campaign..." [Key informant, head of health centre]

“...Lack of community mobilization was main barrier for equitable access to use of PC..." [Key informant, NTDs focal points]

“...Low coverage of PC could be associated with students' absenteeism associated with drugs sideeffects on the deworming day, and school dropout of female students..." [Key informant, primary health care unit-in charge]

“...In our setting, parents did not get well engaged into PC program in an active manner; which resulted in lack of awareness and ownership of PC programme..." [CDD, HEW]

"...Even CDDs do not explain why they distribute drugs being distributed..." [Community member]

Security challenge

"...Some kebeles were left to be reached due to security challenges; which resulted in interruption of MDA due to ethnic clashes ..." [Key informant, NTDs focal point] 
Scheduling of MDA

Lack of treatment round schedule out of working hours affect communities to access PC.

"...Most importantly, the health system did not give adequate time to perform community mobilization about MDA; it was done just after orientation given to deworming team at zone level. The main reason was due to limited funding to conduct mobilization and community engagement adequately especially for SCH-STH programs..." [Key informant, NTD program director]

"...The MDA day should be longer than the usual days ( 3 days) to include some individual who are absent during the MDA day..." [Community member, SAC]

“...Since MDA campaign was done during specific periods, this resulted in overlapping with busy working hours of communities..." [Key informant, health center head]

"..The adequacy and duration of mobilization and community engagement was inadequate for creating awareness ..." [Key informant, primary health care unit-in charge]

Mobile nature of community and scatter pattern of households

CDDs had to travel long-distance within their respective kebeles to reach out to all segments of the communities due to the mobile nature of the community and scatter pattern of households. Also, a significant number of participants stated that distributing drugs at a central point in a nomadic setting could not bring the required coverage in this setting.

. "...Due to the movement of people from place-to-place and scatter pattern of household's settlement, CDDs should move long distance to reach out to their community. This situation is aggravated by lack of transport facilities in the area..." [Key informant, health center head]

"...Often we distribute drugs at a central point, this does work in the nomadic setting since people move from place-to-place..." [CDD, HEW]

Lack of infrastructure and resource

Access of PC to communities has been affected due to a lack of resources, as illustrated below.

"...Lack of infrastructure and resources (road and money) were barriers to equitable access to PC..." [CDD, HEW]

"...Even we paid out from our pocket for mobile costs even for the motor bicycle to get around the points of distribution ..." [CDD, community member]

Low school attendance 
Significant number of participants mentioned that in areas where low school attendance exists, especially in nomadic and remote settings, with exclusive school-based deworming all children could not access to PC.

"...Children out of school did not access to albendazole but they took zithromax drug at health post level..." [CDD, Community member]

Study participants mentioned different barriers related to the acceptability of PC, as stated with the following utterances.

Living in a semi-urban area

"...Most students who refused drugs were individuals living in semi-urban areas. This could be due to people in these areas considered they knowledgeable about health issue..." [Key informant, NTDs focal point]

Rumor and drugs' side-effects

A substantial number of participants revealed that rumor and fears of drugs' side-effects are often associated with praziquantel was mentioned as a potential barrier for drug uptake.

“...Sometimes conflicts happened between drug distributors and recipients during MDA campaign due to side-effect of praziquantel. This often resulted in interruption of MDA as well as injury..." [CDD, HEW] “...Even though teachers and health workers informed students to take food for MDA before one day, most of them would be absent at school on MDA campaign day due to fear of drug's side-effects..." [SAC, Jinka town]

"...MDA was delayed and interrupted in four districts of South Omo zone related to rumor and fears of drugs' side-effects..." [Key informant, NTDs focal point]

"...Some parents came to MDA sites to stop the process and fight with CDDs, especially when side-effects occurred in children..." [CDD, HEW]

“...Many students had feared to take drugs; some think drugs may harm or kill them..." [SAC, Jinka]

"....Most of my colleagues refused to take the drug due to fear of drugs' side-effects..." [School-age children]

"..Many students did not take drugs if they observe drugs' side-effect while their colleagues took drugs..." [Key informant, teacher]

"..Drug distributor didn't start the MDA early in the morning; this aggravated the side-effect of drugs due to hungry..." [KII, school director] 
"...Many individuals may take drugs without having food. Food should be available on the deworming day or MDA should be done in January and February..." [Key informant, women and child issues department head]

Refusal of treatment

Participants mentioned that some individuals refuse to receive drugs.

“...Usually adolescent males and elders $(\geq 60)$ individuals refuse to take drugs..." [CDD, HEW]

Misconception

Different misconceptions were revealed by the study participants, as quoted below.

"...Few people think that the drugs are delivered for trial purpose, especially when side-effect of drugs appeared..." [CDD, community member]

“...People perceived as drugs should not be distributed to the community without a diagnosis of the diseases - community members thaink as taking drugs without the disease being diagnosed may get them sick ..." [Key informant, NTDs program manager]

"...People said that drugs have an adverse effect on sexuality desire ..." [Community drug distributor, community member]

"...Some people felt as they are healthy and disease may appear if they took PC drugs, and also they think drug may harm them..." [Key informant, NTDs manager]

"...Students think that drugs may not meet quality standard so that thought as it harm them..." [Community member, SAC]

Misbelief

Study participants stated potential misbeliefs that could affect the uptake of PC. Communities relate MDA with religious issue mainly with the number " 666 ".

"...Although a significant number of people realized the importance of drugs, substantial numbers of people relate MDA with religious aspects such as " 666 " - relating the number with evil purpose [illuminate]..." [Key informant, primary health care unit-in charge]

"...Many individuals mentioned religious issues as a reason for not taking drugs. They believe that God can save us, and no need to take drugs..." [CDD, community member]

"...There are some extremist religious leaders who promote people not to take drugs..." [CDD community member] 
"...There are some private pharmacy owners who discourage people from not take drugs..." [CDD, HEW]

Lack of parents' consent

Distributing drugs without the consent of parents adversely affect the acceptance of PC.

“...Members of the community ask why drugs distributed without permission of parents..." [Drug distributor, teacher]

"...Parents usually command their children not to take drugs without their permission..." [Drug distributor, HEW]

\section{Lack of awareness}

Lack of community awareness potentially affect drug uptake.

"...The main problem-related acceptability of PC was lack of community awareness due to lack of financial funding to conduct community mobilization..." [Key informant, NTD program manager]

"...Some people thought that why drugs were given without diagnosis of disease. Many people even did not know the purpose of drugs. Besides, lack of media coverage on NTDs and MDA also affected the implementation of MDA..." [Key informant, kebele leader]

"...Misunderstanding due to lack of community mobilization and awareness towards side-effects of drugs was the possible main reason for the interruption of drugs..." [CDD, HEW]

“...My child was a victim of drugs' side-effects - my neighbor informed me that your child may die due to side-effects of drugs...." [CDD, community member]

“...For me, I noticed the advantage and disadvantage of PC - when I see side-effects, I feel as bad, and if not, I feel as good..." [SAC]

“...Students spilled out drugs after given by the CDDs. I heard that one child passed on due to drugs' sideeffects..." [Community member]

"... a substantial number of parents thought they can treat their children at a health facility when they get sick, no need for mass drug administration. And children and parents did know the about purpose, sideeffect of drugs and benefit of drugs..." [Key informant, primary school head]

"...I took drugs, and in fact, I like to take drugs, but some individuals oppose to take the drugs due to lack of awareness among parents and children on the purpose of the MDA..." [Community member]

“...The CDD did not educate us about the benefit of drugs..." [SAC]

“....Many of my colleagues doesn't know the benefit of PC, but I'm still taking the drugs..." [SAC] 
"...Sometimes teacher forced students to swallow drugs instead of providing health education regarding the purpose of swallowing drugs; this resulted in student to escape from the school..." [SAC]

“...Even teachers do not get well informed about PC - do not participate in MDA training..." [School director]

Gender and cultural issues

Focus group participants pointed out that gender and cultural norms that could affect acceptance and use of PC.

“..Some women need permission from their husband to take drugs due to cultural reason..." [Community member]

"...In nomadic and remote settings, there is a cultural norm that could make children keep cattle in a nomadic setting so that SAC does not attend school when a treatment round scheduled..." [Key informant, NTDs focal point]

“...Usually males CDDs are selected in some districts due to husbands' influences..." [Key informant, health centre head]

Distrust of government

Distrust of government and health services could potentially affect equitable use of PC.

"...People thought as drug drugs are provided for political purpose, and they did not take drugs due to distrust of the health system and government..." [Community member, SAC]

Low attention is given to NTDs and PC

"...PC intervention has been implemented for many years, however people are saying other interventions, such as WASH and vector control should be implemented. For example, 50\% of the community did not have clean water; many people are taking water from river..." [Community member]

Lack of ownership of the PC program

“...Since NTDs programs depend on donors, lack of ownership of PC program among implementers and community members affect the implementation of MDA..." [NTDs focal point]

“...Some CDDs consider MDA as a source of income..." [Key informant, NTDs focal point]

Effective coverage of drugs adversely affected by different factors, as revealed below.

Planning, coordination, and supportive system 
Study participants mentioned that access and uptake of PCT were affected by planning, coordination and supportive system.

"...Very tight time has been given to conduct MDA to minimize periderm cost. This resulted in community members and teachers not to be well informed about the MDA ..." [Key informant, primary health care unit-in charge]

"...Lack of coordination remained as a challenge for the community to be not informed due to inadequate times to educate the community..." [Drug distributor, HEW]

"...I would say that the main problem exists within the health system - the health system did not give adequate time to aware the community..." [CDD, HEW]

"..The vertical nature of MDA programs adversely affects our planning to conduct it timely. It resulted in an overlapping of different programs..." [Key informant, primary health care unit-in charge]

Lack of motivation

"...The per-diem we have been paid was inadequate - we are working in hardship setting, even we did not have money to move from pace-to-place. We only received a small per-diem during training. So, this does not motivate us to reach all segments of our community..." [CDD, community member]

"...CDDs leave out from the MDA role mainly due to lack of per-diem, which resulted in CDDs not get motivated..." [Key informant, health center head]

"...In the school-based deworming, teachers were not collaborative as they seek incentive..." [Drug distributor, HEW]

"...We are not motivated by leadership of the health system; the per-diem payment was unfair, not paid equally for equal work. We worked hard but those who were not on work more paid than us..." [CDDs, HEW]

“...CDDs usually leave the program due to lack of incentive..." [Key informant, NTDs focal point].

\section{Facilitators to equitable access and use to PC}

Availability of drugs at no-cost in most endemic districts, presence of community structure, partners support to train CDDs, experience on MDA, and availability of community volunteers were important facilitators to equitable access and use of PCT. The following anecdotes vividly illustrate this.

“...I thank the government for delivering drugs at free of charge..." [Community member]

"...Nowadays, we gained experience on how to conduct MDA. For instance, we learned how to manage religious-related misconception..." [Key informant, district health office head] 
"...Even if it was inadequate, drug distributors informed the community about the purpose of MDA, and where and when it should be distributed before one day of MDA using town criers..." [Community member].

\section{Suggested solutions to improve equity in access and use of PC}

Participant suggested the followings solutions improve equity of MDA in remote and nomadic settings where frequent low coverage reported: Enhance partnership; improve supervision and follow-up, parents should be engaged in MDA, involve village chief in training, arrange visiting schedule in other possible ways, CDDs willingness to give time for MDA campaign, arrange scheduling visits to reach people at their workplace, creating national MDA day, home to-home visit, and planning mop-up activities.

“...There should be adequate time to inform the community, and improve partnership for funding..." [CDD, HEW]

"...Parent should be well informed about the drug and should provide adequate food before going to school..." [Teacher]

“...If parents were of consented about MDA, drugs uptake among students will be improved ..." [CDD, HEW] "...If community people were adequately informed about the purpose and benefit of drugs, the coverage of drug possibly would be improved..." [Key informant, village chief]

"...Drugs uptake can be increased if awareness creation and promotion in the community was performed using banner..."- [Key informant, head of the health center]

“...Participating religious leaders into MDA could help to improve acceptance of MDA..." [CDD, HEW]

"...Being as a role model was crucial to educate and mobilize the community. For example, I took drugs and noticed the impact of the drug on my health and it helped me to educate the community..." [CDD]

"...If the drugs were given in home-to-home base even at a place where the individuals exist, access and use drugs among community will be improved..." [Community member]

"...The kebele administrator should be well informed and be part of the training to understand the purpose of MDA and collaborate in MDA campaign..." [CDD, HEW].

\section{Discussion}

As ensuring equity in PC is critical to reaching the elimination goals of NTDs, there is the need to understand the factors surrounding the implementation of MDA. Given NTDs are targeted for elimination by 2030; implementation of PC should consider setting of the interventions to reach all segments of the populations. This study explored the perspectives and experiences' of stakeholders regarding barriers, 
facilitators, and solutions to equitable access and use of PC towards the control and elimination of NTDs in nomadic and remote settings of Southern Ethiopia to inform decisions made on the PC program. In this study, four domains (availability, accessibility, acceptability, and effective coverage) were considered to understand the implementation of MDA.

Our study revealed that lack of resources (financial, human, communication, and vehicle) affect the equity of PC coverage in terms of drug availability and CDDs' motivation. For instance, due to lack of finance, CDDs pay out from their pocket for transport and phone expenses -and this affects their motivation to reach around their communities. The health system should support CDDs to keep their motivation through incentives and supervision. This agrees with the findings of systematic reviews and studies done in Kenya and Bangladesh [21-24].

It is known that the coverage of PC could be limited by the number of people who can access it. This study revealed that inadequate information, mobilization, and community engagement adversely affect equitable access and use of PC. This is possibly happened because limited access and use of information and community engagement hinder people to get informed and know about the purpose of drugs. This finding is consistent with the finding of a study conducted in Bangladesh, which stated that "communication and information gaps between CDDs and community people were found as a barrier to the utilization and coverage of MDA" [23]. Also, a study conducted in India corroborates the findings of our study [21]. Moreover, studies conducted in Kenya and Zambia revealed that contextually-appropriate community engagement strategies were vital for the uptake of drugs by encouraging a sense of program ownership, trust, and demand $[22,25]$. Further, scheduling MDA also affects the access and use of PC due to lack of treatment round schedule that meet busy working hours of the community. This is in line with the study conducted in Coastal Kenya [26, 27]; and evidence explored by researchers stated that "schedule of MDA that do not match communities' work time schedule affect MDA" [28].

On the other hand, though resources are available and accessible, drugs may not be used if the population does not accept them. Hence, acceptability including non-financial factors, such as culture, beliefs, religion, and gender aspects that relate to people's perceptions of the worth of health services impact the equity of PC [29]. Our study identified that perceiving deworming drugs as safe was important for MDA uptake. On the contrary, fearful perceptions and beliefs about PC were fueled by rumors disseminated in the community. This finding is supported by the finding of studies conducted in Kenya and Bangladesh, where perceptions and experiences related to side-effects of drugs affect the uptake of drugs in the community $[22,23]$. Moreover, the findings of our study suggest that misconceptions and misbelief adversely affect equitable access and use of drugs. This might be due to people perceived as drugs are provided for family planning and it may cause infertility and provide for an evil purpose. Finding our study is consistent with studies conducted in Coastal and Western Kenya [26, 27, 30, 31].

Also, in this study, participants revealed that lack of knowledge on NTDs and PC made it difficult for them to accept the medicines [26]. Additionally, our study found that poor planning in terms of adequate time and schedule affect the MDA coverage since CDDs could not get people at home. This result is in line 
with the finding of other studies [26, 28]. Furthermore, this study explored that uptake of PC can be affected by mistrust of government related to the drugs. This finding is consistent with the finding of a study conducted in Western Kenya [32].

Likewise, our study explored that security challenges hinder accessibility to reach communities affected by NTD. This is because the capacity of health service is limited by the number of people who can reach and use it. This finding is supported by a study conducted in Western Kenya [27]. Furthermore, our study also revealed that the movement of people from place-to-place, scatter pattern of $\mathrm{HHs}$, and low school attendance of children as potential barriers for equitable access of PC in the nomadic setting. This finding is mainly because nomadic communities have a habit of moving place-to-place and a culture of allowing children to keep cattle at file while CDDs visit their home. Also, the distribution of drugs at a central point in these settings could not be a good platform to reach those who require drugs. This finding is supported by a study conducted in Bangladesh [23].

Similarly, our study revealed that effective coverage of drugs was affected by weak planning, leadership, and support system and coordination. This finding is consistent with the finding of a systematic review and meta-analysis and a study conducted in Tigray [31, 33].

On the other hand, findings of our study suggest the presence of community structure (health development army), presence of community health workers, awareness creation, religious and cultural organization, and availability of partners to train drug distributors and deliver drugs for free acted as drivers to equitable access and use of PC. This finding is consistent with the finding of systematic reviews [27, 32, 33]. Most importantly, awareness creation through community participation would be impactful to improve uptake of PC. Our study also revealed decentralization of government structure to the smallest point (kebele) and support system facilitate uptake of PC. The findings of our study are consistent with evidence explored from reviews of studies conducted in different countries and in Kenya $[24,25,33]$.

Concerning limitations of the study, first the purposive selection of study participants might resulted in selection bias. Secondly, social desirability bias may perhaps affected the response of the participants. On the other hand, the study could have been strengthened by conducting both focus groups and key interviews to participate all types of stakeholders.

\section{Conclusions}

This study explored potential barriers that could affect efforts in equitable implementation of MDA. Also, facilitators and solutions were revealed to ensure no one left behind from PC in nomadic and remote settings of Southern Ethiopia to inform PC program. Given NTDs are targeted for elimination by 2030 as part of the sustainable development goals; implementation of PC should consider the setting of the interventions particularly in nomadic and remote areas to reach all segments of the populations. Most importantly, information, mobilization, and community engagement; the mobile nature of the nomadic community, and the high level of low school attendance should take special consideration when MDA is 
planned in these settings. Moreover, the impact of combined MDA models (school-based and communitywide) with tailored community mobilization and awareness campaign on coverage of praziquantel and mebendazole or albendazole in nomadic settings need to be studied. The South Omo zone health department should work in collaboration with partners and the community to address the barriers explored. Further, our study findings may be useful in improving implementation of MDA in other similar settings.

\section{Declarations}

\section{Ethics approval and consent to participate}

Ethical approval was granted from the Institutional Research Ethics Review Board of Arba Minch University, College of Medicine and Health Sciences, Ethiopia (reference number: CMHS- 12032750/111). Participation in the survey was voluntary, and oral and written consents were obtained from study participants before the data collection. Upon arrival in the district, there was a meeting with the district's health office head and village chief, where the purpose of the survey was explained and verbal permission was obtained to perform the survey. Participants in KIls and FGD sessions were given brief health education on the importance of regular periodic deworming, environmental sanitation, and personal hygiene to prevent NTDs in their community at the end of data collection. However, there was no incentive reward for being part of the survey, but participants in the FGDs received a bottle of soft drink, which could worth $\$ 12$ (412.36 ETB).

\section{Consent for publication}

Participants remained anonymous during data entry and analysis, and no individuals' identity can be revealed upon publication.

\section{Availability of data and materials}

The data analyzed for this study is available from the corresponding author upon reasonable request.

\section{Competing interests}

The authors declared that they have no competing interests.

\section{Funding}

This work received financial support from USAID and UK Aid and facilitated by the ARNTD small grant program with support from the Coalition for Operational Research on Neglected Tropical Diseases (CORNTD). The study was conducted with the full responsibility of the authors.

\section{Authors' contributions}


MA made the original draft and involved in the conception. All authors made a significant contribution to the work reported, whether that is in the study design, execution, acquisition of data, analysis and interpretation. In addition, all authors have read, critically reviewed and approved the final manuscript.

\section{Acknowledgments}

The authors would like to sincerely thank the secretariat of the African Research Network for Neglected Tropical Diseases (ARNTD), study participants, data collectors, and administrative officials, without whom this study could not be possible.

\section{References}

1. World Health Organization. Working to overcome the global impact of neglected tropical diseases: first WHO report on neglected tropical diseases. World Health Organization; 2010.

2. Wang X, Zhang L, Luo R, Wang G, Chen Y, Medina A, et al. Soil-transmitted helminth infections and correlated risk factors in preschool and school-aged children in rural southwest China. PLoS One. 2012 Sep 27; 7(9):e45939.

3. World Health Organization. The Expanded Special Project for Elimination of Neglected Tropical Diseases (ESPEN) 2017 Annual Report.

4. World Health Organization. Towards universal coverage for preventive chemotherapy for neglected tropical diseases: guidance for assessing "who is being left behind and why": working draft for further piloting during 2018-2019. World Health Organization; 2017.

5. World Health Organization. First WHO report on neglected tropical diseases: working to overcome the global impact of neglected tropical diseases. InFirst WHO report on neglected tropical diseases: Working to overcome the global impact of neglected tropical diseases 2010 (pp. 172-172).

6. Deribe K, Meribo K, Gebre T, Hailu A, Ali A, Aseffa A, et al. The burden of neglected tropical diseases in Ethiopia, and opportunities for integrated control and elimination. Parasites \& vectors. 2012 Dec 1; $5(1): 240$.

7. World Health Organization. Preventive chemotherapy in human helminthiasis. Coordinated use of anthelminthic drugs in control interventions: a manual for health professionals and programme managers. World Health Organization; 2006.

8. Sachs JD, Hotez PJ. Fighting tropical diseases. SCIENCE-NEW YORK THEN WASHINGTON-. 2006 Mar 17; 5767:1521.

9. Assembly G. United Nations: Transforming our world: The 2030 agenda for sustainable development. Tech. Rep. 1; 2015.

10. Dean L, Ozano K, Adekeye O, Dixon R, Fung EG, Gyapong M, et al. Neglected Tropical Diseases as a 'litmus test'for Universal Health Coverage? Understanding who is left behind and why in Mass Drug Administration: Lessons from four country contexts. PLoS Neglected Tropical Diseases. 2019 Nov 21; 13(11):e0007847. 
11. Molyneux DH. Neglected tropical diseases: now more than just 'other diseases'-the post-2015 agenda. International health. 2014 Sep 1; 6(3):172-80.

12. Webster JP, Molyneux DH, Hotez PJ, Fenwick A. The contribution of mass drug administration to global health: past, present and future. Philosophical Transactions of the Royal Society B: Biological Sciences. 2014 Jun 19; 369(1645):20130434.

13. Federal Democratic Republic of Ethiopia Ministry of Health. Second Edition of Ethiopia National Master Plan for Neglected Tropical Diseases. Addis Ababa, Ethiopia; 2016.

14. World Health Organization. Accelerating work to overcome the global impact of neglected tropical diseases: a roadmap for implementation: executive summary. World Health Organization; 2012.

15. Federal Democratic Republic of Ethiopia Ministry of Health. Unpublished report of preventive chemotherapy distribution. Addis Ababa, Ethiopia; 2018.

16. Tong A, Sainsbury P, Craig J. Consolidated criteria for reporting qualitative research (COREQ): a 32item checklist for interviews and focus groups. International journal for quality in health care. 2007 Dec 1; 19(6):349-57.

17. Ethiopia. Office of the Population, Housing Census Commission. Summary and statistical report of the 2007 population and housing census: population size by age and sex. Federal Democratic Republic of Ethiopia, Population Census Commission; 2008.

18. Central statistical agency (2013) Population Projection for Ethiopia 2007-2037. Addis Ababa, Ethiopia.

19. Braun V, Clarke V. Using thematic analysis in psychology. Qualitative research in psychology. 2006 Jan 1; 3(2):77-101.

20. World Health Organization. Tracking universal health coverage: first global monitoring report. World Health Organization; 2015 Jul 21.

21. Babu BV, Satyanarayana K. Factors responsible for coverage and compliance in mass drug administration during the programme to eliminate lymphatic filariasis in the East Godavari District, South India. Tropical doctor. 2003 Apr; 33(2):79-82.

22. Legge H, Kepha S, Prochazka M, Halliday K, Pullan R, Gwayi-Chore MC, et al. Implementer and recipient perspectives of community-wide mass drug administration for soil-transmitted helminths in Kwale County, Kenya. PLOS Neglected Tropical Diseases. 2020 Apr 20; 14(4):e0008258.

23. Nath TC, Padmawati RS, Murhandarwati EH. Barriers and gaps in utilization and coverage of mass drug administration program against soil-transmitted helminth infection in Bangladesh: An implementation research. Journal of infection and public health. 2019 Mar 1; 12(2):205-12.

24. Krentel A, Gyapong M, Mallya S, Boadu NY, Amuyunzu-Nyamongo M, Stephens M, et al. Review of the factors influencing the motivation of community drug distributors towards the control and elimination of neglected tropical diseases (NTDs). PLoS neglected tropical diseases. 2017 Dec 6; 11(12):e0006065.

25. Silumbwe A, Halwindi H, Zulu JM. How community engagement strategies shape participation in mass drug administration programmes for lymphatic filariasis: The case of Luangwa District, 
Zambia. PLoS neglected tropical diseases. 2019 Nov 27; 13(11):e0007861.

26. Kusi C, Steinmann P, Merten S. The fight against lymphatic filariasis: perceptions of community drug distributors during mass drug administration in coastal Kenya. Infectious Diseases of Poverty. 2020 Dec; 9(1):1-1.

27. Odhiambo GO, Musuva RM, Odiere MR, Mwinzi PN. Experiences and perspectives of community health workers from implementing treatment for schistosomiasis using the community directed intervention strategy in an informal settlement in Kisumu City, western Kenya. BMC public health. 2016 Dec; 16(1):1-2.

28. Krentel A, Gyapong M, Ogundahunsi O, Amuyunzu-Nyamongo M, McFarland DA. Ensuring no one is left behind: Urgent action required to address implementation challenges for NTD control and elimination. PLoS neglected tropical diseases. 2018 Jun 7; 12(6):e0006426.

29. Bivol S, Gh T, Mosneaga A, Soltan V, Domente S, Habicht J, et al. Barriers and facilitating factors in access to health services in the Republic of Moldova. Copenhagen: WHO Regional Office for Europe. 2012.

30. Odhiambo GO, Musuva RM, Atuncha VO, Mutete ET, Odiere MR, Onyango RO, et al. Low levels of awareness despite high prevalence of schistosomiasis among communities in Nyalenda informal settlement, Kisumu City, Western Kenya. PLoS Negl Trop Dis. 2014 Apr 3; 8(4):e2784.

31. Mulugeta A, Gebregergs GB, Asfaw S, Yemane D, Mitiku M, Meresa B, et al. Coverage, social mobilization and challenges of mass Zithromax administration campaign in South and South East zones of Tigray, Northern Ethiopia: A cross sectional study. PLoS neglected tropical diseases. 2018 Feb 26; 12(2):e0006288.

32. Omedo M, Ogutu M, Awiti A, Musuva R, Muchiri G, Montgomery SP, et al. The effect of a health communication campaign on compliance with mass drug administration for schistosomiasis control in western Kenya-the SCORE project. The American journal of tropical medicine and hygiene. 2014 Nov 5; 91(5):982-8.

33. Silumbwe A, Zulu JM, Halwindi H, Jacobs C, Zgambo J, Dambe R, et al. A systematic review of factors that shape implementation of mass drug administration for lymphatic filariasis in subSaharan Africa. BMC public health. 2017 Dec 1; 17(1):484. 